\title{
Variativity of the Transport System at Intercity Passenger Transport from the Demand
}

\author{
Dolia Kostiantyn \\ Department of GIS, Land and Real Estate Appraisal, O. M. Beketov National University of Urban Economy in Kharkiv, Kharkiv, Ukraine \\ Email address: \\ c.dolya@ukr.net \\ To cite this article: \\ Dolia Kostiantyn. Variativity of the Transport System at Intercity Passenger Transport from the Demand. International Journal of Data \\ Science and Analysis. Vol. 3, No. 6, 2017, pp. 77-84. doi: 10.11648/j.ijdsa.20170306.13
}

Received: October 9, 2017; Accepted: October 30, 2017; Published: November 25, 2017

\begin{abstract}
At this stage of development of intercity passenger transportion, there is a need to take into account fluctuations in demand for the services of carriers, which takes place over time. These fluctuations in demand are mostly tied to the onset of a period of nationwide or religious celebrations, the onset of a period of mass holidays, sports and cultural events of state or interstate significance, and so on. Therefore, such existing fluctuations in demand of passengers for the use of public routes in long-distance communication should be taken into account when planning the activity for the management of passenger traffic. In order to meet the needs of passengers for transportation, taking into account the available fluctuations in demand, certain decisions can be taken on the changes in the parameters of the components of the transport system. Such changes include changes in the number or type of rolling stock, timetables, changes in traffic patterns, the introduction of temporary routes, restrictions on the purchasing power of passengers with the help of changing the cost of travel, and so on.
\end{abstract}

Keywords: System of Routes, Transportation Efficiency, Fluctuations in Passenger Correspondence, Transport Process

\section{Introduction}

The role of transport and its infrastructure is very important in the overall system of economic relations of any society. The relations between legal entities and individuals, their development and versatility are largely based on information, material, financial and other flows. Wherein physical changes in the location of people are also very important. For this purpose, passenger transportation systems are being formed and are functioning. These systems consist of separate subsystems of different modes of transport, which work together and compete in the market for population transfer services. The predecessors Ata M Khan (2007), Ibrahim Seedat (2007) and Yves Crozet (2009) determined in their works [1-3] that the reliability and efficiency of industrial, cultural and other processes in society depends to a large extent on how efficiently these systems operate.

It should be noted that passenger transport systems embody the production capacity with their infrastructure on the one hand and people, passengers, on the other hand. If the interest of the first named group lies in the economic interests, in obtaining maximum profit, then the other side, namely people are interested in a fast, convenient and cheap transport service. That is, if the first try to get the maximum revenues from transportation with a minimum of costs and it requires an increased cost of travel, then people want a cheap and reliable service. This contradiction hinders the interaction of carriers and passengers at first glance, but on the other hand ensures the struggle of opposites, which is the driving force of any development. This processes were considered by such scientists as Yves Crozet (2009), Indrajit Ghosh (2016) and Joseph Schwieterman (2016) [3-5].

At different stages of development of passenger transport, scientists and practitioners were directed to such a compromise of their aspirations, in which the transportation process ensured the satisfaction of economic interests of carriers on the one hand. And on the other hand, the transportation process would be affordable, reliable and would meet the purchasing power of people. The search for various options for technologies of interaction between the society and the transport industry is constantly staying at the stage of searching for the best possible methods of organizing transportation. This process is permanent, it is based on analytical, experimental and even intuitive approaches. Therefore, the authors Ibrahim Seedat (2007), Tao Li Affiliation (2016), Prasolenko O., Lobashov O., 
Galkin A. (2015) and Grigorova T., Davidich Yu., Dolya V. (2015) considered that any research on the improvement of the methods of arranging passenger transportation is relevant [2, 6-8].

At this stage of development of intercity passenger route transport, there is a need to take into account fluctuations in demand over time for the services of carriers. These fluctuations in demand are mostly tied to the onset of a period of nationwide or religious celebrations, the onset of a period of mass holidays, sports and cultural events of state or interstate significance, and so on. Therefore, such existing fluctuations in the demand of passengers for the use of public routes in long-distance communication should be taken into account when planning the activity for the management of passenger traffic.

In order to meet the needs of passengers for transportation, taking into account the available fluctuations in demand, certain decisions can be taken on the changes in the parameters of the components of the transport system. Such changes include changes in the number or type of rolling stock, timetables, changes in traffic patterns, the introduction of temporary routes, restrictions on the purchasing power of passengers with the help of changing the cost of travel, and so on.

\section{Object of Study}

The object of the study is weekly fluctuations in passenger correspondence in the modern long-distance passenger transport system in Ukraine, and the subject - the patterns of functioning of the given system.

In this study, long-distance passenger transport correspondence, formed in the existing system is considered.

One of the most problematic places is the study of the actual values of permanent long-distance correspondence, which consists in obtaining up to now undefined corrective coefficients used in the calculation of potential correspondence between cities. The received knowledge gives an opportunity in application of a considered method of calculations of correspondence between cities in relation to the market of passenger transportations in Ukraine. Technological audit was carried out in the transport network by collecting statistical information.

\section{Purpose and Objectives of the Study}

The purpose of this work is to formalize the algorithm for mathematical modeling of the transport process of longdistance passenger transportation, taking into account the weekly fluctuations of passenger correspondence.

To achieve the purpose of the work, the following tasks must be solved:

1) to analyze scientific and theoretical approaches to the study of intercity passenger transport systems;

2) formulate the objective function of improving longdistance passenger transportations;

3) mathematically describe the components of the objective function;

4) make a topological scheme of the transport network by mode of transport;

5) determine the capacity of cities relatively to their inhabitants, the number of departures and the arrival of passengers in them;

6) calculate the matrix of the shortest distances and the number of transport correspondences between all possible pairs of cities;

7) form an array of possible routes and with the help of successive culling offer the best version of the longdistance passenger transportation system;

8) check the proposed version of the transportation system by the criterion of total time and fatigue of passengers;

9) conduct experimental studies and assess the adequacy of theoretical models.

\section{Research of Existing Solutions of the Problem}

It should be noted that passenger transport in the social, economic or cultural development of the population is very important. Therefore, the regulation of the provision of transport services to the population should satisfy the possibility of obtaining these services within the limits of the allowable financial, time and physical burden on the passenger. That is, the optimization of the constituent of the efficiency of the operation of long-distance passenger transportation must be in harmony with the socio-economic development of society. It is clear from the stated requirements that dissatisfaction of the demand of passengers for transportation by means of extra-large fare, the lack of a route communication between the transport areas with permanent correspondence, non-observance of driving comfort conditions with increased transport fatigue or the insufficiency of vehicles are unacceptable.

On the one hand, the importance of the social component on long-distance route transportation is undeniable. In accordance with this there is a need for taking balanced decisions on the management of the passenger transportation system. The invention of a compromise between the technical and economic level of satisfying demand and the requirements for maintaining the income-expenditure component of the transport process is an urgent issue.

From considerations of taking a balanced decision on the technical maintenance of fluctuations in demand, there remains a need to determine the feasibility of increasing the potential transport operation of long-distance passenger transport routes by changing the quality or quantity of vehicles on existing routes or introducing additional temporary routes into the route network.

In recent decades of studies of intercity passenger transport systems scientists Grigorova T., Davidich Yu., Dolya V. (2015), A. Andronov, D. Santalova (2009), Grigorova T., Davidich Yu., Dolya V. ( 2015), Park M., Hahn J. (2015) and H. Baik, A. Trani, N. Hinze, H. Swingle, S. Ashiabor, A. 
Seshadri. (2008) modeled their functioning, testing different approaches [8-12]. Some scientists believed that the best passenger transportation system is a system that provides a minimum cost of transportation, namely:

$$
\sum_{i=1}^{n} B_{i} \rightarrow \min
$$

where $B_{i}$ - expenses of $i$-th transport enterprise for passenger transportation;

$n$ - number of transport enterprises.

At the same time, the condition was defined that all passengers should be transported in time and with an established level of convenience, that is:

$$
\sum_{i, j} H_{i j} \rightarrow \text { const (satisfied), }
$$

where: $H_{i j}$ - correspondences from any point of departure $i$ to any point of destination $j$.

Convenience of the trip was mainly due to the fact that the filling of the vehicles $\gamma_{i}$ in each separate one should not exceed the permissible value $\gamma_{\max }$ :

$$
\gamma_{i} \leq \gamma_{\max }
$$

Since the price for travel was determined by the purchasing power of the population and other marketing indicators, the revenues from transportation were accepted in any amount. This approach has placed on the carriers the obligation to transfer all passengers with a specified level of convenience. At the same time, in order to achieve maximum profit, transport enterprises used such technologies, which provided a minimum of costs for carrying out the transportation process.

For some time in the assessment of the functioning of passenger transport systems, the approach in which everything was considered to provide the maximum social component prevailed. In particular, the total time spent by citizens on movement should be minimal, this was claimed by Park M., Hahn J.(2015), Wu C., Han J., Hayashi Y. (2011), Rwakarehe, E. E., Zhong, M., \& Christie, J. (2014) and Vrtic, M., Fröhlich, P., Schüssler, N., Axhausen, K. W., Lohse, D., Schiller, C., \& Teichert, H. Two (2007) [11, 12, 13, 14]:

$$
\sum_{i j} H_{i j} T_{n i j} \rightarrow \min ,
$$

where: $H_{i j}$ - correspondences from any point of departure $i$ to any point of destination $j$;

$T_{n i j}$ - defined time of motion from $i$ to $j$.

However, there were certain restrictions: the carrying capacity of vehicles is limited and permanent:

$$
\sum_{i=1}^{m} A_{i} V_{i} T_{\Pi i}
$$

where $A_{i}-$ number of $i-\mathrm{x}$ vehicles;
$V_{i}$ - operational speed of vehicles;

$T_{\Pi \mathrm{i}}-$ period of use of $i-\mathrm{x}$ vehicles for all kinds of transportation.

Similarly as in the previous approach it was considered that the prices for the trip are fixed and are determined by marketing parameters.

Such an approach does not correspond to a certain extent to the interests of transport enterprises and is inherent for society with a left model of the economy.

In the modern period of development of civilizational relations $[15,16]$, an approach, based on the assertion that the best technology of passenger transportation is the one that with all existing restrictions minimally tires passengers, prevails. The hypothesis was grounded that the passenger does not accurately determine and pay attention to the duration of the trip and its convenience. His subconscious mind to some extent combines these parameters. The passenger is tired and this fatigue determines for him the attractiveness of the trip. It was determined that a longer, but more comfortable trip, attracted the passenger more.

In this case, the objective function has the following form:

$$
\sum_{i j k} H_{i j k}(I F L)_{i j k} \rightarrow \min ,
$$

where: $I F L_{i j \kappa}$ - the indicator of transport fatigue of the $\kappa-$ th passenger, moving from $i$ to $j$.

In this case as in the previous cases, certain restrictions are imposed, namely:

the transport capability of the means of transport is fixed and limited;

all passengers are transported in time and with a minimum passenger load factor $\gamma$;

pricing, as in the previous cases, is determined by marketing parameters.

In different periods, researchers [17] have established a dependence on the level of fatigue of passengers and the productivity of their activity at work.

\section{Materials and Methods of Research}

Given model of calculations of transport correspondences and means of the communication of passengers between any pairs of cities allows to define streams of passengers on set of routes on chains of their formation.

Regarding the routes of rail transport, the relative error $\varepsilon \varepsilon_{T}$ was $5,83 \%$, and for the routes of road transport $\varepsilon \varepsilon_{\text {ав }}$ amounted to $4,18 \%$. At the same time, the relative error in rail transport in high-speed and conventional routes differed and needs additional specifications.

The objective function of improving long-distance passenger transportation is to maximize the $K O$ - the utility of the given system, namely:

$$
K O=f\left(D_{c} ; B_{c}\right) \rightarrow \max ,
$$

where: $D_{c}-$ system revenues; 
$B_{c}$ - system expenses.

In turn, the system's $B_{c}$ revenues are:

$$
B_{\Pi}=\sum_{i j k} H_{i j k}(P R)_{i j k},
$$

where: $(P R)_{i j k}$ - fare for the movement from $i$ to $j$ spent by $\kappa$ - th passenger.

System expenses:

$$
B_{c}=B_{F}+B_{\Pi} \text {, }
$$

where: $B_{F}-$ costs of of transport enterprises;

$B_{\Pi}$ - incomplete income of passengers due to their transport fatigue.

In turn, the expenses of the system consist of the incomplete income of the aggregate of passengers due to their transport fatigue $B_{w}$, the total payment for transport work taking into account the budgetary surcharges $B_{v}$ and the expenses of transport enterprises $B_{F}$.

$$
B_{c}=B_{w}+B_{v}+B_{F} \text {, }
$$

Wherein

$$
B_{w}=\sum_{i j k} H_{i j k} P_{i j k} N D_{k},
$$

where: $N D_{k}$ - the share of national income per $\kappa-$ th passenger per day.

$$
B_{v}=\sum_{i j k} H_{i j k}(P R)_{i j k},
$$

where: $P R$ - the total fare of the $k$ - th passenger from $i$ to $j$, taking into account budgetary surcharges.

$$
B_{F}=\sum_{i j k} H_{i j k} S_{i j k},
$$

where: $S_{i j k}-$ cost of transportation of the $k-$ th passenger from $i$ to $j$.

As for the passenger transport technologies, the revenues of the system are the monetary expenses of passengers for travel. That is, the expenses of passengers are the income of the system $D_{c}$.

$$
D_{c}=B_{v}=\sum_{i j k} H_{i j k}(P R)_{i j k}
$$

In general

$$
K O=\sum_{i j k} H_{i j k} S_{i j k}+\sum_{i j k} P_{i j k} N D_{k} \rightarrow \min ,
$$

To determine the size of transport correspondences between the cities of iteration and absorption, the wellknown principle of gravity models can be used. Namely:

$$
H_{i j}=\frac{H_{n i}^{x 1} H_{n j}^{x 2} k_{j} d_{i j}}{\sum_{i=1}^{n} H_{n j}^{x 2} K_{j} d_{i j}},
$$

where: $K_{j}$ - balancing coefficient.

$$
d_{i j}=\frac{1}{L_{i j}^{x_{3}^{\prime}}}
$$

where: $L_{i j}$ - distance between cities $i$ and $j$,

$x_{3}$ - indicator of the degree of function, which requires research in each case.

Or

$$
d_{i j}=\frac{1}{T_{i j}^{X_{3}^{\prime \prime}}}
$$

where: Tij - travel time between cities $i$ and $j$,

$x_{3}$ - indicator of the degree of function, which requires research in each case.

The attraction function in the hyperbolic form can be clarified by the dependence:

$$
d_{i j}=\frac{1}{2 \sqrt{2 \pi}} e^{t_{x i j}^{x_{3}^{\prime \prime}} /(2 \delta)^{2}} \text { or } d_{i j}=\frac{1}{2 \sqrt{2 \pi}} e^{t_{x i j}^{x_{3}^{\prime}} /(2 \delta)^{2}}
$$

To clarify the attraction function between cities $i$ and $j$, it is possible to use field observations in which are the following parameters, relatively to the city of departure $i$ and city of arrival $j$ :

population in cities $i$ and $j$;

total daily number of residents leaving from $i$ and arriving at $j$ per day;

the distance between $i$ and $j$ and at the same time the movement time from $i$ and $j$ on the network of the current routes;

the estimated number of $H_{i j}$ for various indicators $x_{3}$ and $x_{3}$; the amount of $H_{i j}$ per day, according to observations that can be primed on the reporting figures for the sale of tickets.

A comparison of the calculated $H_{i j}$ and $H_{i j}$ from observations on the magnitude of the absolute and probable deviations makes it possible to make a conclusion about the advisability of using indicators $x_{3}^{\prime}$ and $x_{3}^{\prime \prime}$ in the models for determining $d_{i j}$. For this it is proposed to use the dependence (16) with the definition of distance as a factor of correspondence resistance. According to the results, the following dependence was obtained (20):

$$
H_{i j}=H_{B i} H_{n i} d_{i j} k^{d a y}
$$

where $H_{b i}$ - number of departures from the city $i$;

$H_{n j}$ - number of arrivals to the city $j$;

$k^{d a y}$-balancing coefficient corresponding to the calculated day of the week;

$d_{i j}$ - function of attraction from the city $i$ to the city $j$. 
To assess the adequacy of the proposed scientific approach, full-time measurements were carried out on the routes of passenger traffic on different sections of routes. The $k^{d a y}$ parameters for Monday, Friday, Saturday and Sunday have been empirically obtained, which provided an opportunity to make calculations and determine the ratio of the calculated and valid rates of passenger correspondence (Table 1).

Table 1. Comparison of the current and calculated passenger traffic on the sections of the transport network.

\begin{tabular}{|c|c|c|c|c|c|c|c|c|c|}
\hline \multirow{3}{*}{ Type of transport } & \multirow{3}{*}{ Arc of network } & \multicolumn{8}{|c|}{ Passenger traffic by weekdays, pass / day } \\
\hline & & \multicolumn{4}{|c|}{ Field $H_{i j}$} & \multicolumn{4}{|c|}{ Estimated $\boldsymbol{H}_{i j}^{\prime}$} \\
\hline & & Mo & Fr & Sa & Su & Mo & Fr & Sa & Su \\
\hline Railway & $16-28$ & 372 & 472 & 365 & 409 & 352 & 447 & 345 & 387 \\
\hline Railway & $34-12$ & 4212 & 5518 & 3664 & 4675 & 4316 & 5654 & 3755 & 4791 \\
\hline Railway & $08-63$ & 2068 & 2668 & 1985 & 2254 & 1824 & 2353 & 1751 & 1988 \\
\hline Railway & $09-14$ & 916 & 1172 & 843 & 1035 & 1020 & 1306 & 938 & 1153 \\
\hline Railway & $07-79$ & 3076 & 3907 & 2738 & 3384 & 2988 & 3795 & 2659 & 3287 \\
\hline Automobile & $16-28$ & 124 & & & & 124 & 157 & 122 & 136 \\
\hline Automobile & $34-12$ & 482 & & & & 482 & 631 & 419 & 535 \\
\hline Automobile & $08-63$ & 338 & & & & 338 & 436 & 324 & 368 \\
\hline Automobile & $09-14$ & 96 & & & & 96 & 123 & 88 & 108 \\
\hline Automobile & $07-79$ & 412 & & & & 412 & 523 & 367 & 453 \\
\hline$\ldots$ & $\ldots$ & $\ldots$ & & & & $\ldots$ & & & \\
\hline
\end{tabular}

Taking into account the received data of field observations, it was revealed that there are fluctuations in the volume of passenger transportation, depending on the day of the week.

Comparison of actual and theoretical values of passenger traffic on the chains of the transport network was carried out by the criterion of relative error $\mathcal{E} \mathcal{E}$.

$$
\varepsilon \varepsilon=\frac{\left|H_{i j}^{\prime}-H_{i j}\right| 100}{H_{i j}},
$$

where $H_{i j}$ and $H_{i j}^{\prime}$ - current and calculated passenger traffic respectively, pass/day.

\section{Research Results}

For the modeling of passenger flows between cities $i$ and $j$ it is not enough to know the correspondence between them $H_{i j}$. It should be taken into account that they can be implemented by different routes, different modes of transport. In this case, the passenger selects a particular route taking into account its attractiveness. The attractiveness function of route $Z$ relatively to other possible routes depends on the travel time on this route, the cost of travel and the convenience of staying in the cabin:

$$
f_{z}=f\left(\left(\tau_{z} ; \tau_{c e p}\right) ;\left(P R_{z} ; P R_{c e p}\right) ;\left(I F L_{z}^{\prime} ; I F L_{c e p}\right)\right),
$$

where: $\tau_{\mathrm{z}}$ and $\tau_{\text {cep }}$ - accordingly, the travel time on route $Z$ and the average travel time on alternative routes;

$P R_{z}$ and $P R_{\text {cep }}$ - respectively, the fare on route $Z$ and the average fair for alternative routes;

IFL $_{\mathrm{z}}$ and $I F L_{c e p}$ - measure both the fatigue level of passengers on route $Z$ and the average fatigue level on alternative routes.

Together with this, the value of the attractiveness function $f_{z}$ and the weight of its components depends on their ratio:

$$
f_{z}=\frac{\tau_{c e p} \kappa_{\tau} P R_{c e p} \kappa_{P R}(I F L)_{c e p} \kappa_{I F L}}{\tau_{z} P R_{z}(I F L)_{z}^{\prime}},
$$

where: $k_{P R}, k_{I F L}, k_{\tau}$ respectively, the coefficients that take into account the weight of the corresponding parameter.

Wherein, depending on the time period of the trip, whether it is day or night, priorities change. For example, during the day $\kappa_{\tau}$ prevails, and at night $k_{I F L}$ prevails. The values of these coefficients depend on the state of society, its purchasing power, season, etc. and have to be specified by special sociological research. All transport correspondences $H_{i j}$ are distributed along alternative routes. Moreover, only part of $H_{i j}$ stays on route $Z$.

$$
H_{i j z}=\frac{f_{z}}{\sum_{z=1}^{r} f_{z}} H_{i j},
$$

where: $z$ - number of alternate routes.

In this case:

$$
H_{i j z}=\frac{\frac{\tau_{c e p} k_{\tau}(P R)_{c e p} k_{P R}(I F L)_{c e p} k_{I F L}}{\tau_{z}(P R)_{z}(I F L)_{z}^{\prime}} f_{z}}{\sum_{z=1}^{r} \frac{\tau_{c e p} k_{\tau}(P R)_{c e p} k_{P R}(I F L)_{c e p} k_{I F L}}{\tau_{z}(P R)_{z}(I F L)_{z}^{\prime}}} H_{i j} .
$$

Given number of transport correspondences on each route $Z H_{i j z}$ is only a calculated value. It reflects the demand and can be realized under a certain proposal. That is, there should be such a proposal of the capacities of routes in which these correspondences can be realized. At the same time, extra proposals can unbalance the transport process and the modeling of the value of this proposal can be in the form of functions of passenger capacity and traffic intensity of vehicles. Any significant deviations from the rational value of supply or demand can negatively affect the transport 
process. This determines the feasibility of modeling the functioning of the routes in such a way to be able to determine the functional relationship between the transportation needs $H_{i j}$ and the transportation offer, which can be represented as carrying capacity.

The transportation opportunities on the route $P M_{z}$ are mostly expressed by the formula:

$$
H M_{z}=\varsigma_{z} A_{i} V_{i} T_{n i j},
$$

where: $\mathrm{g}_{\mathrm{z}}$ - passenger capacity of vehicles on the route $Z$;

$A_{i}$ - number of $i-\mathrm{x}$ vehicles;

$V_{i}$ - operational speed of vehicles;

$T_{n i} j-$ period of use of $i-\mathrm{x}$ vehicles for all kinds of transportation.

It is desirable that the possible $W_{z m}$ and necessary transport work $W_{z p}$ on route $Z$ corresponds to transport capacities and

$$
W_{z p}=\sum_{i j} H_{i j z} L_{i j}=\sum_{z=1}^{r} g_{z} A_{z} V_{z} T_{p}
$$

where: $L_{i j}-$ distance between cities $i$ and $j$,

$T_{p}$ - period of use of $i-\mathrm{x}$ vehicles for all kinds of transportation;

$H_{i j}$ - correspondences from any point of departure $i$ to any point of destination $j$.

In turn, transport correspondences $H_{i j}$ can be distributed among alternative routes in proportion to their alternative offer, that is:

$$
H_{i j z}=\frac{H_{i j} g_{z} A_{z} V_{z}}{\sum_{z=1}^{r} g_{z} A_{z} V_{z}}
$$

Taking into account the influence on $H_{i j z}$ of the attraction functions of the sets of routes $Z$, connecting $i$ and $j$, the function takes the following form:

$$
H_{i j z}=\frac{H_{i j} g_{z} A_{z} V_{z} \frac{\tau_{c e p} k_{\tau}(P R)_{c e p} k_{P R}(I F L)_{c e p} k_{I F L}}{\tau_{z}(P R)_{z}(I F L)_{z}^{\prime}}}{\sum_{z=1}^{r} g_{z} A_{z} V_{z} \frac{\tau_{c e p} k_{\tau}(P R)_{c e p} k_{P R}(I F L)_{c e p} k_{I F L}}{\tau_{z}(P R)_{z}(I F L)_{z}^{\prime}}}
$$

It is clear that the cities of arrival $j$ or dispatch $i$ of passengers are located on the transport network so that the routes are duplicated partially or completely. At the same time, it is possible to move in such a way that market mechanisms will act in such a way that the supply and demand on alternative routes will be aligned, that is, the transport work $\mathrm{W}_{z}$, proposed on route $Z$ corresponds to the potentially possible $\mathrm{W}_{M z}$ on this route. The proposed transport work on route $Z$ can be represented as a carrying capacity, that is:

$$
W_{3 Z}=g_{z} A_{z} V_{z} T_{c}
$$

where: $T_{c}$ - time of movement of vehicles on the route.

Possible transport work on the route depends on $H_{i z j z}$. In this case, only a pair of $i$ and $j$ that take place on route $Z$ are considered, and only those correspondences $\mathrm{H}_{\mathrm{ij}}$ on route $\mathrm{Z}$ exist.

The correspondence of the proposed and possible transport work on the set of routes can be some constant, acting on all routes and determined by a certain level of economic development, purchasing power and the like. That is, on any route $Z$ :

$$
W_{M Z}=\sum_{i z ; j z} H_{i z ; j z} L_{z ; j z}
$$

Or

$$
W_{M Z}=\sum_{z ; j z} \frac{H_{z ; j z} g_{z} A_{z} V_{z} \frac{\tau_{c e p} k_{\tau}(P R)_{c e p} k_{P R}(I F L)_{c e p} k_{I F L}}{\tau_{z}(P R)_{z}(I F L)_{z}^{\prime}}}{\sum_{z=1}^{r} g_{z} A_{z} V_{z} \frac{\tau_{c e p} k_{\tau}(P R)_{c e p} k_{P R}(I F L)_{c e p} k_{I F L}}{\tau_{z}(P R)_{z}(I F L)_{z}^{\prime}}} L_{z ; j z},
$$

Using the hypothesis that the ratio $\mathcal{E}$ of modes of transport is a constant, it is possible to determine parameters of routes $q_{z} ; A_{z} ; V_{e z}$ from the dependency:

$$
\begin{aligned}
& \frac{W_{M Z}}{W_{3 Z}} \rightarrow \text { const }=\varepsilon, \\
& \frac{1}{g_{z} A_{z} V_{z} T_{c}} \sum_{z ; j z} \frac{H_{z ; j z} g_{z} A_{z} V_{z} \frac{\tau_{c e p} k_{\tau}(P R)_{c e p} k_{P R}(I F L)_{c e p} k_{I F L}}{\tau_{z}(P R)_{z}(I F L)_{z}^{\prime}}}{\sum_{z=1}^{r} g_{z} A_{z} V_{z} \frac{\tau_{c e p} k_{\tau}(P R)_{c e p} k_{P R}(I F L)_{c e p} k_{I F L}}{\tau_{z}(P R)_{z}(I F L)_{z}^{\prime}}} L_{z ; j z}=\varepsilon
\end{aligned}
$$

The $k^{d a y}$ value is obtained for Monday, Friday, Saturday, and Sunday, which have the meanings 1,$12 ; 1,17 ; 0,94$ and 1,07 , respectively.

\section{Discussion}

Evidence of the possibility of applying the chosen model to the system of long-distance passenger traffic in Ukraine can be attributed to the strengths of this study. New information has been obtained on the modeling of transport route systems for the transport of passengers between cities within the investigated system. In favor of this statement, modern scientific achievements, as set forth in the reviewed literature, attest. It is under these circumstances that it is expedient to use models for predicting the parameters of the system's functioning in practical conditions. The use of the data obtained with respect to the optimal values of the invented means provides an opportunity to take into account the qualitative performance indicators and planning parameters of the reviewed transport system. In view of the above, new information has been obtained on the system studied, in particular - on the planning of performance 
indicators for the functioning of the transport system for the transportion of passengers on common routes between cities. The obtained results can be used to carry out calculations for the transportation of passengers between cities in Ukraine. This is more advantageous in comparison with analogues due to:

a) ensuring the registration of social and economic characteristics of the population of Ukraine;

b) it is possible to increase the productivity by optimizing the use of the route network;

c) satisfaction of economic interests of the transport industry.

The drawback of the conducted research and the obtained results are the following: the failure to take into account the fact of existing passenger correspondence between the cities, which is made with the use of passenger cars. However, it should be noted that the purpose of the work was to study the correspondence of passengers on public routes. Also, when receiving data on permanent correspondences, the fluctuations in correspondence related to seasonal changes in the mobility of the population were not taken into account. At the same time, the work records the socioeconomic status of passengers. It should be noted that the introduction of the results of the study into the passenger transport system will not bear additional financial burdens on transport enterprises or passengers.

The accurately calculated value of passenger long-distance transport correspondence on public routes allows to plan the interaction between systems of various modes of transport to meet the needs of the country's population for movement within the investigated system. At the same time, it is possible to improve the quality of the financial flows of enterprises by optimizing the allocation of resources over time throughout the whole passenger system.

There are difficulties in applying the results of the study. This is connected with the fact that the application of the results requires the modernization of the existing transport infrastructure. The state of the system, in which it will require transport companies to provide bigger volumes of transportation services is possible.

\section{Conclusions}

The given above algorithm for the formation of the transport system of intercity passenger transport is based on modern achievements of science and practice, and takes into account the patterns of distribution of transport correspondence between cities from the transport network, the functions of attraction between cities, the number of inhabitants and their purchasing power, etc. Unlike the existing approaches to solving of similar problems of modern passenger transport systems, proposed algorithm is based on a mathematical description of the joint activity of not only routes, but also their impact on public activities, taking into account transport fatigue.

The sequence and content of research on the rational parameters of the intercity passenger system can be used in similar actions for the formalization of the mentioned system in the consideration of international route systems. At the same time, transport systems of a number of countries can formally form a common system of territory united by any principle.

\section{References}

[1] Khan, A. M. (1981). II. Intercity passenger transportation: energy efficiency and conservation case study. Transportation Planning and Technology, 7(1), 1-9.

[2] Seedat, I. (1973). Implementing the 2007 Public Transport Strategy and Action Plan: transportation. Civil Engineering= Siviele Ingenieurswese, 15(9), 13-16.

[3] Crozet, Y. (2009). The prospects for inter-urban travel demand (Vol. 14). OECD Publishing.

[4] Nokandeh, M. M., Ghosh, I., \& Chandra, S. (2015). Determination of Passenger-Car Units on Two-Lane Intercity Highways under Heterogeneous Traffic Conditions. Journal of Transportation Engineering, 142(2), 04015040.

[5] Schwieterman J. (2016) Intercity Buses: 2015 Was A Smooth Ride. New Geography Zuse Institute Berlin,; Markus Reuther Affiliation: Zuse Institute; Kerstin Waas Affiliation (2016): Integrated Optimization of Rolling Stock Rotations for Intercity Railways, Transportation Science, v50 n3

[6] Li, T. (2016). A Demand Estimator Based on a Nested Logit Model. Transportation Science.

[7] Prasolenko, O., Lobashov, O., \& Galkin, A. (2015). The Human Factor in Road Traffic City. International Journal of Automation, Control and Intelligent Systems, 1 (3), 77-84.

[8] Grigorova, T., Davidich, Y., \& Dolya, V. (2015). Transport Fatigue Simulation of Passengers in Suburban Service. International Journal of Automation, Control and Intelligent Systems, 1 (2), 87-99.

[9] Andronov, A., \& Santalova, D. (2009). On Nonlinear Regression Model for Correspondence Matrix of Transport Network. In Selected papers of the International Conference Applied Stochastic Models and Data Analysis (pp. 90-94).

[10] Grigorova, T., Davidich, Y., \& Dolya, V. (2015) Assessment of elasticity of demand for services of suburban road passenger transport. Technology audit and production reserves, $3(2$ (23)), 13-16.

[11] Park, M., \& Hahn, J. (2015). Regional freight demand estimation using Korean commodity flow survey data. Transportation Research Procedia, 11, 504-514.

[12] Wu, C., Han, J., \& Hayashi, Y. (2011). Airport attractiveness analysis through a gravity model: A case study of Chubu International Airport in Japan. In Proceedings of the Eastern Asia Society for Transportation Studies The 9th International Conference of Eastern Asia Society for Transportation Studies, 2011 (pp. 419-419). Eastern Asia Society for Transportation Studies.

[13] Vrtic, M., Fröhlich, P., Schüssler, N., Axhausen, K. W., Lohse, D., Schiller, C., \& Teichert, H. (2007). Two - dimensionally constrained disaggregate trip generation, distribution and mode choice model: Theory and application for a Swiss national model. Transportation Research Part A: Policy and Practice, 41(9), 857-873. 
[14] Baik, H., Trani, A., Hinze, N., Swingle, H., Ashiabor, S., \& Seshadri, A. (2008). Forecasting model for air taxi, commercial airline, and automobile demand in the United States. Transportation Research Record: Journal of the Transportation Research Board, (2052), 9-20.

[15] Rwakarehe, E. E., Zhong, M., \& Christie, J. (2014). Development of a Freight Demand Model for the Province of Alberta Using Public Sources of Data. Procedia-Social and Behavioral Sciences, 138, 695-705.
[16] Fornalchyk, Y., Bilous, A., \& Demchuk, I. (2015). The Model of Correspondence of Passenger Transportation on the Basis of Fuzzy Logic. ECONTECHMOD: an international quarterly journal on economics of technology and modelling processes, 4.

[17] Li, T. (2016). A Demand Estimator Based on a Nested Logit Model. Transportation Science. 